\title{
THE EFFECT OF LIMITED VERSUS EXTENDED AXILLARY LYMPH NODES DISSECTION IN THE DEVELOPMENT OF POST-MASTECTOMY MORBIDITY
}

\author{
Ahmed N Abdulnabi \\ MB,ChB, CABS, Specialist of General Surgery, AL-Fayhaa Teaching Hospital, Basrah, IRAQ.
}

\begin{abstract}
Breast cancer is a common malignancy in female, modified radical mastectomy is widely used for the management of this tumour. Axillary lymph nodes dissection is accompanied by frequent postoperative morbidity including wound infection, paresthesia, seroma and upper limb lymphedema.

This is a comparative study that was conducted to evaluate the frequency of postoperative morbidity in a limited and extended axillary lymph nodes dissection.

One hundred and fifty patients were treated by modified radical mastectomy for invasive ductal carcinoma of the breast between January 2008 and October 2015 in Al-Fayhaa Teaching Hospital. This sample was divided into two groups; the first fifty patients were managed with limited N1 axillary dissection while the other one hundred patients with extended N2 axillary dissection. The postoperative morbidity in the form of wound infection, paresthesia, seroma formation and upper limb lymphedema were analyzed in respect to the N1 or N2 axillary lymph nodes dissection.

The highest occurrence was in the age group between 36 and 45 years. Wound infection develops in $16 \%$ of patients in the first group and $12 \%$ in the second group. Seroma occurred in $20 \%$ in the first group and $23 \%$ in the second group. Paresthesia was obviously higher in the second group $(19 \%)$ when compared with $4 \%$ in the first group. Lymphedema occurred more in the second group (26\%), and less in the first group (4\%).

In conclusion, limited axillary lymph nodes dissection during modified radical mastectomy for patients with no or few axillary lymph nodes involvement is associated with low postoperative morbidity.
\end{abstract}

Key words: Mastectomy,Axillary lymph nodes,Morbidity, Limited dissection, Extended dissection

\section{Introduction}

Q reast carcinoma is still the most B common malignancy among women ${ }^{1}$. Since the mid-1940s, the incidence of new cases has been steadily increasing ${ }^{2}$. Following bronchogenic carcinoma, breast cancer in woman is the second leading cause of cancer death ${ }^{3}$. Breast conservative surgery and modified radical mastectomy are the most popular procedures for breast cancer management ${ }^{4}$, they are complemented by axillary lymph nodes dissection for curative and prognostic goals ${ }^{5}$. Many complications can be seen after breast cancer surgeries including seroma formation, wound infection and paresthesia which occur early and upper limb lymphedema that occur later ${ }^{6-8}$.

The aim of this study is to evaluate the effect of extent of axillary lymph nodes dissection in the development of postoperative complications.

\section{Patients and methods}

This prospective comparative study was carried out in Al-Fayhaa Teaching Hospital, Department of Surgery in Basrah, with a total number of one hundred and fifty breast cancer patients who were diagnosed and operated upon during the period between January 2008 and October 2015. All patients' parameters 
were fully evaluated and interpreted. After taking a written informed consent, all patients with stages IB, II and IIIA infiltrating ductal carcinoma were operated upon by modified radical mastectomy with excision of N1 (1-3) or N2 (4-9) axillary lymph nodes according to the disease stage and extent of lymph node involvement which were evaluated preoperatively by ultrasonography and intraoperatively during surgical procedure. The patients were classified to have N1 or N2 nodal excision according to the postoperative histopathological reports that shows the number of lymph nodes resected within the mastectomy specimen. One hundred and fifty breast cancer patients were divided into two groups according to the TNM classification ${ }^{9}$, the first group contains fifty patients with early breast carcinoma who were subjected to a limited axillary lymph nodes dissection and their histopathology reports showed (1-3) lymph nodes in the specimen (N1), while the second group contains one hundred patients who were subjected to extended axillary lymph nodes dissection and their specimens contained (4-9) lymph nodes (N2).

Patients with N3 (more than 10 lymph nodes) dissections were excluded from this study because of their limited number, and also those with matted lymph nodes in which we couldn't assess the number of these lymph nodes in the specimen.

All patients in this study were discharged home in the second or third postoperative day and were followed up for at least two years after surgery in the outpatient department or private clinic.

Data were analyzed statistically using SPSS program.

\section{Results}

The age distribution of the patients is summarized in Table I, which shows that the highest age group is between 36 and 45 years, while the lowest one is below 25 year.

Table I: Age distribution of patients underwent surgery

\begin{tabular}{|l|c|c|}
\hline Age in years & No. of patients & Percentage \\
\hline Less than 25 & 0 & $0 \%$ \\
\hline $25-35$ & 11 & $7.34 \%$ \\
\hline $36-45$ & 67 & $44.66 \%$ \\
\hline $46-55$ & 38 & $25.33 \%$ \\
\hline $56-65$ & 25 & $16.67 \%$ \\
\hline Above 65 & 9 & $6 \%$ \\
\hline Total & 150 & $100 \%$ \\
\hline
\end{tabular}

Fifty patients have N1 axillary lymph nodes dissection and one hundred patients having N2 axillary lymph nodes dissection during modified radical mastectomy as shown in Table II.

Table II: Extent of axillary lymph node dissection

\begin{tabular}{|l|c|c|c|}
\hline Group & No. of lymph node dissection & No. of patients & $\%$ of patients \\
\hline One & $1-3$ & 50 & $33.34 \%$ \\
\hline Two & $4-9$ & 100 & $66.66 \%$ \\
\hline Total number & 150 & $100 \%$ \\
\hline
\end{tabular}

Twenty patients $(13.33 \%)$ developed postoperative wound infection which is slightly higher in group one (16\%) as shown in Table III. 
Table III: The number and percentage of patients who developed wound infection

\begin{tabular}{|l|c|c|c|}
\hline Group & $\begin{array}{c}\text { No. of patients who } \\
\text { developed wound } \\
\text { infection }\end{array}$ & $\begin{array}{c}\text { No. of patients } \\
\text { for each group }\end{array}$ & $\begin{array}{c}\% \text { of wound infection in } \\
\text { each group }\end{array}$ \\
\hline One & 8 & 50 & $16 \%$ \\
\hline Two & 12 & 100 & $12 \%$ \\
\hline Total & 20 & 150 & \\
\hline
\end{tabular}

The chi-square statistic is 0.4615 . The p-value is 0.496906 . The result is not significant $(\mathrm{p}>0.05)$.

Postoperative seroma developed in 33 patients (22\%) and it is nearly equal in both groups as shown in the Table IV.

Table IV: The number and percentage of patients who develop seroma

\begin{tabular}{|l|c|c|c|}
\hline Group & $\begin{array}{c}\text { No. of patients who } \\
\text { developed seroma }\end{array}$ & $\begin{array}{c}\text { No. of patients } \\
\text { for each group }\end{array}$ & $\begin{array}{c}\text { \% of seroma in each } \\
\text { group }\end{array}$ \\
\hline One & 10 & 50 & $20 \%$ \\
\hline Two & 23 & 100 & $23 \%$ \\
\hline Total & 33 & 150 & \\
\hline
\end{tabular}

The chi-square statistic is 0.1748 . The $\mathrm{p}$-value is 0.675859 . The result is not significant $(\mathrm{p}>0.05)$.

Twenty-one patients developed paresthesia (14\%) and it is more in group two as shown in table $\mathrm{V}$.

Table V: The number and percentage of patients who develop paresthesia

\begin{tabular}{|l|c|c|c|}
\hline Group & $\begin{array}{c}\text { No. of patients who } \\
\text { developed paresthesia }\end{array}$ & $\begin{array}{c}\text { No. of patients for } \\
\text { each group }\end{array}$ & $\begin{array}{c}\text { \% paresthesia in } \\
\text { each group }\end{array}$ \\
\hline One & 2 & 50 & $4 \%$ \\
\hline Two & 19 & 100 & $19 \%$ \\
\hline Total & 21 & 150 & \\
\hline
\end{tabular}

The chi-square statistic is 6.2292 . The p-value is 0.012566 . The result is significant $(\mathrm{p}<0.05)$.

Twenty-eight patients developed lymphedema (18.66\%) and it is obviously higher in group two as shown in Table VI.

Table VI: The number and percentage of patients who developed lymphedema

\begin{tabular}{|l|c|c|c|}
\hline Group & $\begin{array}{c}\text { No. of patients who } \\
\text { developed } \\
\text { lymphedema }\end{array}$ & $\begin{array}{c}\text { No. of patients for } \\
\text { each group }\end{array}$ & $\begin{array}{c}\text { \% of lymphedema in } \\
\text { each group }\end{array}$ \\
\hline One & 2 & 50 & $4 \%$ \\
\hline Two & 26 & 100 & $26 \%$ \\
\hline Total & 28 & 150 & \\
\hline
\end{tabular}

The chi-square statistic is 10.6265 . The p-value is 0.001115 . The result is significant $(\mathrm{p}<0.05)$. 


\section{Discussion}

Surgical options for the management of breast cancer patients are many, modified radical mastectomy with axillary dissection is the commonest procedure used nowadays ${ }^{10}$. Axillary lymph nodes dissection is still an essential step of the radical and conservative breast cancer surgery ${ }^{11}$. Many articles discussed the postoperative breast cancer morbidity and categorized them as early and late postoperative complications.

Many risk factors increases the incidence of wound infection such as improper sterilization, malnutrition, drain, improper patient's hygiene, and frequent wound dressing. There is no rule of extensive axillary dissection in the development of wound infection as shown in Table III, and it is slightly more with $\mathrm{N} 1$ than N2 dissections (not significant), and generally it is higher $(13.33 \%)$ when compared with Lang C J study $(3.6 \%)^{12}$.

Postoperative seroma formation is the most frequent complication after breast cancer surgery, although it is considered nowadays as a side effect of surgery rather than a complication ${ }^{13}$. Following modified radical mastectomy, the incidence of seroma formation is about $50 \%{ }^{14}$, and in the study done by Gonzalez EA et al it was $15.8 \%{ }^{15}$, in the present study it was $22 \%$. The rich lymphatic channels that drain the breast to the axillary lymph nodes establishes the gradient for seroma formation postoperatively within the closed dead space of the breast and axillary bed ${ }^{16,17}$. There are many risk factors implemented in the development of seroma formation like; extent of axillary lymph node dissection, number of positive lymph nodes involvement, intraoperative lymphatic channels ligation, preoperative chemotherapy and postoperative arm activity ${ }^{9,18-20}$. Petrek et al, in a prospective randomized trial showed that the most significant factor that leads to seroma formation postoperatively was the number of axillary lymph node involvement and extent of their dissection ${ }^{21}$. Most breast surgeon's try to remove the drain postoperatively when the drainage volume reduced to less than $20-50 \mathrm{ml}$ daily and sometimes, the patients can be discharged early from the hospital with drain in situ ${ }^{22}$. The seroma formation in this comparative study is nearly equal in the two groups and it was $20 \%$ for $\mathrm{N} 1$ and $23 \%$ in N2 dissections (the result is not significant). In the first group, the drain volume in most patients became less than $30 \mathrm{ml} /$ day within 4 to 5 days postoperatively, while it became less than $30 \mathrm{ml}$ within 8 to 9 days postoperatively in the second group. Also the drain was left for less than 7 days in the first group and for nearly 10 days in the second group, that's why the percentage of seroma formation was nearly equal in both groups but in general the more disruption and destruction of the lymphatic channels and flow (in extended dissection), the more possibility of seroma formations.

Twenty-one patients (14\%) developed paresthesia in the upper arm medially and/or axilla. It has a wide range of occurrence, Abdullah et al study reported about $14.3 \%{ }^{23}$. In the current study, $4 \%$ of the patients in the first group and 19\% in the second group developed paresthesia and this is significant result because of extensive axillary lymph nodes dissection. Persistent numbness after mastectomy due to intercostobrachial nerve injury is frequently occurs with axillary dissection than with conservative surgeries ${ }^{24}$.

Lymphedema is a collection of lymphatic fluid in the affected limb as a result of inadequate lymphatic flow and transport due to the obstruction or damage of lymphatic vessels ${ }^{25,26}$. Disipio et al discussed a meta-analysis of 72 studies in 2013, the estimated post-mastectomy lymphedema incidence was $16.6 \%$, and when data restricted to prospective cohort studies, it was $21.4 \%{ }^{27}$. The upper limb lymphedema generally has wide range of occurrence between $2 \%$ to $40 \%$ among 
females with breast cancer surgery ${ }^{28}$. In this study the incidence was $18.6 \%$ and there is obvious difference in the percentage of lymphedema development which is more in the second group $26 \%$ compared with the first group (4\%), this is also a significant result because of extensive axillary lymph nodes dissection. American Cancer Society and other references summarize the most important risk factors that mostly play role in the development of lymphedema after breast cancer surgery, which are; extent of axillary dissection, number of lymph nodes involvement, axillary radiation after axillary dissection, axillary recurrence, infection and hematoma ${ }^{5,10,29}$.

The findings of the current study conduct that as the extent of axillary lymph nodes dissection increased, the more probability of lymphedema, paresthesia and more postoperative serous fluid drainage in the tube drain.

\section{Conclusion}

From the above findings, it is concluded that limited axillary lymph nodes dissection in early breast cancer which is diagnosed and assisted preoperatively is associated with low post-mastectomy morbidity when compared with extensive unwanted axillary lymph nodes dissection.

\section{References}

1. Williams S. N., Connell P. R. McCaskie A. W., "Bailey and Love's Short Practice of Surgery", 27th Ed., Replika Press Ptv. Ltd, India p. 1610, 2018

2. Pogson CJ, Adwani A, Ebbs SR. Seroma following breast cancer surgery. Eur J Surg Oncol 2003; 29:711-7.

3. Jemal A, Siegel R, Ward E, Hao Y, Xu J, Murray T et al. Cancer statistics, 2008. CA Cancer J Clin. 2008;58:71-96.

4. Lumachi F, Brandes AA, Burelli P, Basso SM, lacobone M, Ermani M. Seroma prevention following axillary dissection in patients with breast cancer by using ultrasound scissors:a prospective clinical study. J Eur Surg Oncol 2004; 30:526-30.

5. Throckmorton AD, AskgardGiesmann J, Hoskin TL, Bjaranson H, Donohue JH, Boughey JC, et al. Sclerotherapy for the treatment of postmastectomy seroma. Am J Surg. 2008;196(4):541-4

6. Sorensen LT, Horby J, Friss E, Pilsgaard B, Jorgensen T. Smoking as a risk factor for wound healing and infection in breast cancer surgery. Eur J Surg Oncol 2002; 28:815-20.

7. Awan MS, Dahri FJ, Laghari AA. Surgical sites infection in elective surgery. J Surg Pak 2011; 16:97-101.

8. Clark B, Sitzia J, and Harlow W, "Incidence and risk of arm oedema following treatment for breast cancer: a three year followup study, " QJM, 2005; 98(5): 343-8.

9. Townsend C. M., Beauchamp R. D., Evers B. M., Mattox K. L., "Sabiston Textbook of Surgery the Biological Basis of modern Surgical Practice",17th Ed., Elsevier Inc., p. 2316, 2004.

10. McLaughlin SA. Chapter 40: Lymphedema, in Harris JR, Lippman ME, Morrow M, Osborne CK. Diseases of the Breast, 5th edition. Lippincott Williams and Wilkins, p. 1224, 2014

11. Mulholland M. W., Lillemoe K. D., Doherty G. M., Maier R. V., Simeone D. M., Upchurch G. R., "Greenfield's Surgery Scientific Principles and practice", 5th Ed, Lippincott Williams and Wilkins, p. 2074, 2011.

12. Lanng C, Hoffmann J. Conservative treatment of wound infection after breast cancer surgery. Ugeskr Laeger 2002; 164: 4185-7.

13. Gong $\mathrm{Y}, \mathrm{Xu} \mathrm{J}$, Shao J, Cheng $\mathrm{H}$, Wu X, Zhao D, et al. Prevention of seroma formation after mastectomy and axillary dissection by lymph vessel ligation and dead space closure: a randomized trial. Am J Surg. 2010;200:352-6.

14. Stanczyk M, Grala B, Zwierowicz T, Maruszynski M. Surgical resection for persistent Seroma, following modified radical mastectomy. World Journal of Surgical Oncology 2007; 5:100-4.

15. Gonzalez EA, Saltzstein EC, Riedner CS. Nelson BK. Seroma formation following breast cancer surgery. Breast Journal 2003; 9(5):385-8.

16. Fischer J. E., "Mastery of Surgery", 5th Ed., Lippincott Williams and Wilkins, p. 2283, 2007.

17. Taylor JC, Rai S, Hoar F, Brown H, Vishwanath I. Breast cancer surgery without suction drainage: the impact of adopting a no drains policy on symptomatic seroma formation rates. Eur. J. Surg. Oncol. 2013; 39(4): 334-8.

18. Akinci M, Cetin B, Aslan S, Kulacoglu H. factors affecting seroma formation after mastectomy with full axillary dissection. ActaChir Belg. 2009;109:481-3.

19. Daltrey I, Thomson $\mathrm{H}$, Hussien $\mathrm{M}$ et al. Randomized clinical trial of the effect of quilting latissimusdorsi flap donor site on seroma formation. Brit. J. Surg. 2006; 93(7): 825-30.

20. Chand N, Anna M, Aertssen G, Royal GT. Axillary exclusion a successful technique for reducing seroma formation after mastectomy and axillary dissection. Advances Breast Cancer Ress. 2012;2:1-6.

21. Petrek JA, Peters MM, Nori S, Knauer C, Kinne DW, Rogatko A. Axillary lymphadenectomy. A prospective randomize trial of 13 factors influencing drainage including early or delayed arm mobilization. Arch Surg. 1990;125:378-82.

22. Gupta R, Pate K, Varshney S, Goddard J, Royle GT. A comparisionof 5-day and 8-day drainage following mastectomy and axillary clearance. Eur J SurgOncol. 2001;27:26-30. Doi: 10.1053/ejso.2000.1054.

23. Abdullah TI, Iddon J, Barr L. Prospective randomized controlled trial of preservation of the intercostobranchial nerve during axillary node clearance for breast cancer. Br J Surg 1998; 85 : 1443-5.

24. Stubbiefield MD, Custodio CM. Upper extremity pain disorders in breast cancer. Arch Phys Med Rehabil 2006; 87(3):96-9.

25. Brunicardi F.C., Anderson D. K., Billiar T. R., Dunn D. L., Hunter J. G., Matthews J. B., Pollock R. E., "Schwartz's Principle of Surgery", 10th Ed., McGraw-Hill education, p. 2069, 2014.

26. Cemaly Y, Pusica A, Mehrara BJ. Preventive measures of lymphedema: Separating fact from fiction Jam Coll Surg 2011; 213(4):543-55.

27. DiSipio T, Rye S, Newman B, Hayes S. Incidence of unilateral arm lymphedema after breast cancer: a systemic review and meta-analysis. Lancet Oncol. 2013; 14(6):500-15.

28. Ozalsan C, Kuru B, lymphedema after treatment of breast cancer. Am J Surg 2004:187:69-72.

29. Hayes S, DiSipio T, Rye S, Lopez J, Saunders C, Pyke C, Bashford J, Battistutta D, Newman B. Prevalence and prognostic significance of secondary lymphedema following breast cancer. Lymphatic Research and Biology. 2011; 9(3):135-41. 